\title{
(DES)DEMOCRATIZAÇÃO DO ACESSO À JUSTIÇA POR PESSOAS COM DEFICIÊNCIA AUDITIVA NO BRASIL: UMA REFLEXÃO À LUZ DO PENSAMENTO DE CHARLES TILLY
}

\section{Maria Soledade Soares Cruzes*}

Resumo: O trabalho apresenta-se com objetivo geral de analisar a (des)democratização do acesso à justiça por pessoas com deficiência auditiva no Brasil. Busca-se, inicialmente, esclarecer o conceito de democratização e desdemocratização à luz do pensamento de Charles Tilly. Feito isso, analisa-se, sob a égide da igualdade de oportunidades, avanços legislativos com relação ao acesso à justiça por pessoas com deficiência auditiva. Por fim, visa-se investigar alguns desafios por ela enfrentados confrontando com as ideias do autor mencionado. Consiste em pesquisa bibliográfica, de cunho exploratório, desenvolvida por método dedutivo e análise crítica de textos legislativos e dados governamentais.

Palavras-chave: Democratização. Justiça. Deficiência. Auditiva. Brasil.

\section{(DE) DEMOCRATIZATION OF ACCESS TO JUSTICE BY PEOPLE WITH HEARING DISABILITY IN BRAZIL: A REFLECTION TO THE LIGHT OF THE THOUGHT OF CHARLES TILLY}

\begin{abstract}
The paper presents a general objective of analyzing the (de)democratization of access to justice by hearing impaired people in Brazil. It seeks, initially, to clarify the concept of democratization and de-democratization in the light of the thought of Charles Tilly. Once this is done, analyzes, under the aegis of equal opportunities, legislative advances regarding access to justice for people with hearing impairment. Finally, investigates some of the challenges it faces in confronting the ideas of the author mentioned. It consists of bibliographic research, of an exploratory nature, developed by deductive method and critical analysis of legislative texts and governmental data.
\end{abstract}

Keywords: Justice. Hearing. Disability. Democracy. Brazil.

\section{INTRODUÇÃO}

A Constituição da República Federativa do Brasil de 1988 é responsável pela instituição do Estado Democrático de Direito e por garantir, como direito fundamental, amplo acesso à justiça. O Estatuto da Pessoa com Deficiência (Lei n. 13.146/2015) baseia-se na Convenção sobre os Direitos das Pessoas com Deficiência e alinha-se com o texto

\footnotetext{
* Doutoranda em Direito (UFBA). Mestra em Direito (UFBA). Professora, em regime de dedicação exclusiva, da Universidade Estadual do Sudoeste da Bahia (UESB). Pesquisadora nos grupos de pesquisa "Direito e Sociedade” (UESB) e "Acesso à Justiça” (UFBA). E-mail: msolesc@ hotmail.com
}

Revista Brasileira de Direitos e Garantias Fundamentais | e-ISSN: 2526-0111 | Porto Alegre | v. 4 | n. 2 | p. $38-60$ | Jul/Dez. 2018 
constitucional para estabelecer diretrizes e normas gerais no sentido de assegurar e promover, em condições de igualdade de oportunidades, acessibilidade para essas pessoas, visando à inclusão social e cidadania por meio da garantia e exercício de direitos.

Mas, é preciso refletir se a autoproclamação em Estado Democrático ou a previsão constitucional ou legislativa de tais direitos é suficiente para a garantia de práticas democráticas por parte do Estado e da sociedade brasileira. Propõe-se tal reflexão à luz do pensamento de Charles Tilly acerca da democracia, democratização e desdemocratização.

Nesse sentido, nota-se que, em que pese os avanços alcançados (muitos deles tardios), seja no plano interno, seja no internacional, a pessoa com deficiência auditiva ainda encontra muitas barreiras no que tange a sua acessibilidade à justiça brasileira. É nesse contexto que se apresenta o problema central da pesquisa: em meio a avanços e desafios, em que medida é possível vislumbrar um concreto e democrático acesso à justiça para pessoas com deficiência auditiva no Brasil, sob a égide do pensamento de Charles Tilly?

Para responder a tal questionamento, foi desenvolvida pesquisa bibliográfica e exploratória, por meio da revisão de literatura, concretizada na análise de textos legislativos, constitucionais, obras jurídicas e interdisciplinares, cartilhas, dados governamentais e jurisprudência correlata. Assim, utilizando-se de método dedutivo, passa-se de aspectos gerais a mais específicos, que se concretizam no exame crítico dos desafios para o efetivo acesso à justiça por pessoas com deficiência auditiva, diante das barreiras que lhe são impostas.

Deste modo, no presente trabalho busca-se, inicialmente, refletir sobre os conceitos de democracia, democratização e desdemocratização em Charles Tilly. Feito isso, passa-se à análise de avanços, gerais e específicos, no que tange ao acesso à justiça para pessoas com deficiência no direito brasileiro, principalmente após a Constituição Federal de 1988, à luz da igualdade de oportunidades, apregoada pela Convenção Internacional sobre os Direitos das Pessoas com Deficiência e pelo Estatuto da Pessoa com Deficiência, e levando em consideração a promulgação do Novo Código de Processo Civil (Lei n. 13.105/2015).

Por fim, busca-se pontuar alguns desafios para a concretização da acessibilidade por pessoas com deficiência auditiva à justiça brasileira, como o reconhecimento legal tardio da Língua Brasileira de Sinais e outras barreiras sociais, atitudinais e educacionais, refletindo sobre o grau de extensão da democratização ou desdemocratização neste contexto.

Revista Brasileira de Direitos e Garantias Fundamentais | e-ISSN: 2526-0111 | Porto Alegre | v. 4 | n. 2 | p. $38-60$ | Jul/Dez. 2018 


\section{DEMOCRACIA, DEMOCRATIZAÇÃO E DESDEMOCRATIZAÇÃO EM CHARLES TILLY}

A Constituição da República Federativa do Brasil de 1988 é responsável pela instituição do Estado Democrático de Direito. Como bem ressalta Silva (1988, p. 15), o texto constitucional o acolhe, já em seu art. $1^{\circ}$, como conceito-chave do regime adotado, assim como o fez a constituição portuguesa e a espanhola.

Buscando tais origens, deve-se observar as ideias do constitucionalista português Canotilho (2003, p. 97-98) no sentido de que o Estado de Direito democrático implica em uma ordem de domínio legitimada pelo povo, de modo que o poder do Estado deve ser organizado e exercido em termos democráticos e à luz da soberania popular. Já o jurista espanhol Díaz (1969, p. 41) diferencia o Estado Social de Direito (e o neocapitalismo típico do Welfare State) do Estado Democrático de Direito, que surge como a fórmula institucional de convergência entre democracia e socialismo.

Contudo, Silva (1988, p. 22) adverte que a Magna Carta de 1988 não chegou a estruturar um Estado Democrático de Direito de cunho efetivamente socialista, apesar de ter aberto "as perspectivas de realização social profunda pela prática dos direitos sociais que ela inscreve e pelo exercício dos instrumentos que oferece à cidadania, que possibilita concretizar as exigências de um Estado de justiça social fundado na dignidade da pessoa humana".

Feitas tais considerações, questiona-se: seria suficiente uma autoproclamação de democracia por parte de determinado Estado, de forma contundente, já no primeiro artigo de seu texto constitucional? É a partir de reflexões semelhantes a esta que Tilly (2013, p. 15) propõe o primeiro capítulo de sua obra, intitulado “O que é democracia?”.

Com efeito, o autor apresenta como ponto de partida o fato de a Constituição do Cazaquistão proclamar, já em seu artigo $1^{\circ}$, o Estado Democrático. Ressalta que tal texto foi redigido cinco anos após sua separação da União Soviética, convocada pelo presidente Nursultan Nazarbayev e redigida por seus conselheiros após referendo nacional que revelou maciço apoio ao novo modelo. (TILLY, 2013, p. 13).

Contudo, Tilly (2013, p. 13) observa que em 2005 a Freedom House, uma instituição sediada em Nova York que monitora a democracia, indicou para tal país notas muitos baixas em relação aos direitos políticos e quase tão baixas em relação às liberdades civis. Tilly

Revista Brasileira de Direitos e Garantias Fundamentais | e-ISSN: 2526-0111 | Porto Alegre | v. 4 | n. 2 | p. $38-60$ | Jul/Dez. 2018 
(2013, p. 13) destaca possíveis abusos cometidos pelo presidente Nazarbayev, como eleições suspeitas pelo alto índice de aprovação, influência econômica da família, perseguição à oposição, entre outros.

Tal problemática apresenta-se como pressuposto para outro questionamento trazido por Tilly (2013, p. 20): como é possível decidir se determinado país qualifica-se ou não como democracia? Ao tentar responde-lo, o autor afirma que é possível levar em consideração alguns aspectos.

Inicialmente, aponta a situação política dos regimes por todo o mundo, já que os detentores do poder precisam saber se estão lidando com democracia ou com outros tipos de regime. Por conseguinte, identifica a qualidade de vida das pessoas que vivem nesses regimes, sendo a democracia visualizada como um bem em si mesmo, na medida em que oferece à população de determinado regime o poder de determinar seu próprio destino.

Mas, Tilly (2013, p. 20-21) foca seu trabalho no terceiro aspecto: a explicação da democratização. Propõe-se, então, a explicar o desenvolvimento da democracia e seus impactos sobre a vida coletiva, verificando sua extensão. Nesse sentido, afirma que, para que se possa descrever e explicar variações e mudanças na extensão e no caráter da democracia, é preciso desenvolver uma definição precisa de democracia.

Sendo assim, o autor passa a analisar criticamente algumas definições de democracia. No que tange às abordagens constitucionais - que se concentram sobre as leis sancionadas por determinado regime com relação à atividade política -, Tilly (2013, p. 21) alerta para a possibilidade de discrepâncias entre os princípios afirmados e as práticas cotidianas.

Já a abordagens substantivas são focadas nas condições de vida e de política que um regime promove como bem-estar, liberdade individual, segurança, equidade, igualdade social, deliberação pública e resolução pacífica de conflitos. Mas, Tilly (2013, p. 21) questiona-se sobre como estabelecer critérios de comparação entre esses princípios desejáveis.

As definições procedimentais, por sua vez, isolam determinado conjunto de práticas governamentais para verificar se um regime qualifica-se ou não como democrático. Concentram-se na idéia de que se as eleições realmente promovem mudanças governamentais significativas, indicam a presença de democracia. Mas, na opinião de Tilly (2013, p. 22) opera-se com uma concepção muito estreita de processo político.

Tilly (2013, p. 23) adota, então, como ponto de partida para sua definição de 
democracia, as "abordagens voltadas para o processo", que se pautam em um conjunto mínimo de processos que precisam estar continuamente presentes para que determinada situação possa ser configurada como democrática.

Nesse sentido, faz remissão aos critérios relativos ao processo apontados por Dahl (2009, p. 49-50) para que se caracterize uma democracia. O primeiro, que é o da participação efetiva, pauta-se na igualdade de oportunidades de todos os membros para participar das decisões da associação sobre sua política.

O segundo critério exige que no momento em que a decisão sobre a política for tomada, todos os membros tenham oportunidades iguais e efetivas de voto. O terceiro referese ao entendimento esclarecido que cada membro deve ter, em igualdade de oportunidades, com relação ao aprendizado sobre políticas alternativas relevantes e suas consequências.

Contudo, Dahl (2009, p. 49) observa que o processo democrático dos três primeiros critérios apontados não é fechado, na medida em que o quarto critério (controle da agenda) exige que os membros tenham a oportunidade de escolherem quais assuntos devem ser agendados, estando sempre sujeitos a mudança por decisão dos membros.

Por fim, em contraponto aos modelos históricos de democracia que antecederam o século XX, Dahl (2009, p. 50) aponta o critério da inclusão dos adultos, afirmando que todos, ou pelo menos a maioria dos cidadãos adultos residentes permanentes deveriam ter o pleno direito de cidadãos, implícito ao critério da participação efetiva acima exposto.

Tilly (2013, p. 24) entende, todavia, que a lista de critérios apontadas por Dahl é estática, devendo indicar respostas como "sim" ou "não". Sendo assim, se um regime apontar todos os critérios, é considerado democracia; por outro lado, se algumas não estiverem operando devidamente, não será considerado democracia. Ademais, tais critérios seriam mais adequados para espaços de tempo específicos e não para processos contínuos ou para comparação de regimes.

É nesse contexto que Tilly (2013, p. 25-26) passa a apontar os elementos da democracia, democratização e desdemocratização, sem, contudo, se desvencilhar da abordagem pelo processo. Nesse sentido, simplifica algumas noções como a de Estado (único ou razoavelmente unificado), de cidadãos (todos aqueles que vivem sob a jurisdição do Estado) e de processos políticos públicos (abarcando apenas os que visivelmente mobilizam o poder e a ação do Estado).

Revista Brasileira de Direitos e Garantias Fundamentais | e-ISSN: 2526-0111 | Porto Alegre | v. 4 | n. 2 | p. $38-60$ | Jul/Dez. 2018 
Sob tais pressupostos, Tilly (2013, p. 27) aufere o grau de democracia analisando a extensão na qual o Estado se comporta diante das demandas expressas por seus cidadãos. Nesse sentido, conclui o autor:

[...] um regime é democrático na medida em que as relações políticas entre o Estado e seus cidadãos engendram consultas amplas, igualitárias, protegidas e mutuamente vinculantes. A democratização significa um movimento real no sentido de promover uma consulta mais ampla, mais igualitária, mais protegidas e mais vinculante. Então, obviamente, a desdemocratização significa um movimento real no sentido de uma consulta mais estreita, mais injusta, menos protegida e menos vinculante. (TILLY, 2013, p. 28).

Perceba-se que, na visão de Tilly (2013, p. 28), é possível identificar quatro dimensões de variações entre os regimes. A "amplitude" estende-se desde regimes em que apenas um pequeno segmento da população usufrui de extensos direitos até os que garantem ampla inclusão política de pessoas sob a jurisdição. Pelo critério da "igualdade", por sua vez, varia desde uma grande desigualdade entre os cidadãos e categoria de cidadãos, até uma extensiva igualdade em ambos os casos, não havendo distinções em nome da etnia.

Mas, tais critérios, embora essenciais para a concepção da cidadania, não são suficientes para constituir uma democracia. É que, segundo Tilly (2013, p. 29), ainda é necessária a "proteção" contra a ação arbitrária do Estado, que varia de um extremo em que o Estado usa constantemente seu poder para punir inimigos pessoais ou premiar amigos; a outro, e que todos os cidadãos gozam de um processo público e correto.

Por fim, o "caráter mutuamente vinculante" vai desde o grau em que os requerentes dos benefícios do Estado precisam usar de artifícios como suborno ou influência de terceiros para que suas demandas sejam atendidas; até o grau em que os agentes do Estado tem obrigações claras e instituídas de conceder os benefícios devidos. (TILLY, 2013, p. 29).

Em síntese, à luz do pensamento de Tilly (2013, p. 29-30), a democratização deve ser vista como "a média de um movimento crescente nas quatros dimensões", enquanto a desdemocratização, por decorrência lógica pauta-se no movimento médio decrescente. É pautando em tais conceitos que se pretende arriscar traçar um grau de extensão da democracia no Brasil no que se refere ao acesso à justiça por pessoas com deficiência auditiva, partindo da hipótese de que uma mera abordagem constitucional, concentrada sobre as leis sancionadas, seria insuficiente para compreensão da complexidade do tema.

\section{O PARÂMETRO DA IGUALDADE DE OPORTUNIDADES E OS AVANÇOS NO}

Revista Brasileira de Direitos e Garantias Fundamentais | e-ISSN: 2526-0111 | Porto Alegre | v. 4 | n. 2 | p. $38-60$ | Jul/Dez. 2018 


\section{ACESSO À JUSTIÇA PARA PESSOAS COM DEFICIÊNCIA NO BRASIL}

Um passo inicial para problematizar a democratização do acesso à justiça é a referência à obra clássica de Cappelletti e Garth (1988, p. 08-09), que observam que nos Estados Liberais "burgueses" dos séculos dezoito e dezenove, os procedimentos adotados para solução dos litígios civis refletiam filosofia essencialmente individualista dos direitos. Nesse contexto, o Estado permanecia passivo, abstendo-se com relação a problemas como a aptidão de uma pessoa para reconhecer seus direitos e defendê-los adequadamente.

No que tange ao Brasil, nota-se que, apesar de a Constituição de 1946 ter garantido, em seu art. 141, $\S 4^{\circ}$, que a lei não poderia excluir da apreciação do Poder Judiciário qualquer lesão de direito individual, tal norma só encontra maior viabilidade de se tornar efetiva com a proclamação do Estado Democrático de Direito pela Constituição Federal de 1988.

Além disso, o texto constitucional de 1988 expressa verdadeiro compromisso com o acesso à justiça e aos direitos, sintetizando no art. 5\%, XXXV, que "a lei não excluirá da apreciação do Poder Judiciário lesão ou ameaça a direito". Ou seja, não se trata apenas de lesões individuais, abarcando também as coletivas e as ameaças.

Souza (2011, p. 166) observa, todavia, que o acesso à justiça não se restringe à inafastabilidade do controle jurisdicional; sendo conceito bem mais amplo, na medida em que abarca o direito à decisão, mediante processo devido (CF/88, art. $\left.5^{\circ}, \mathrm{LIV}\right)$ e que seja proferida em tempo razoável (CF/88, art. 5, LXXVIII), fundamentada, eficaz e equitativa.

Nesses moldes, o acesso democrático à justiça envolve não apenas a garantia de "porta de entrada" ao Poder Judiciário (concretizada pela postulação ao Estado-Juiz), sendo indispensável à existência da "porta de saída", decorrente do cumprimento das garantias do devido processo legal, com resultado justo e em tempo razoável. (SOUZA, 2011, p. 26).

Com efeito, no trilhar do caminho de uma revolução democrática da justiça brasileira exige-se tarefa detalhista e árdua, que parte da repaginação do acesso ao direito e à justiça. Neste intento, Santos (2011, p. 39) observa que, para além da concepção tradicional de acesso a algo já existente, a proposta é de "mudar a justiça a que se tem acesso".

Tal mudança só se dará por meio da transformação jurídica e política que envolva, entre outros aspectos: profundas reformas processuais; novos protagonismos e pluralismos jurídicos; renovadas organização e gestão judiciárias; revolução na formação profissional;

Revista Brasileira de Direitos e Garantias Fundamentais | e-ISSN: 2526-0111 | Porto Alegre | v. 4 | n. 2 | p. 38 - 60 | Jul/Dez. 2018 
novas concepções de independência judicial; mais transparência nas relações entre poder judicial, político e mídia; mais densidade nas relações com os movimentos e organizações sociais; cultura jurídica democrática e não corporativa. (SANTOS, 2011, p. 39).

A partir da Constituição Federal de 1988 e todo seu aparato rumo à democratização do acesso à justiça por grupos vulneráveis no Brasil, vários avanços legislativos podem ser observados no que tange às pessoas com deficiência. Toma-se como exemplo a Lei n. 7.853/1989 que, dentre outras medidas, institui a tutela jurisdicional de interesses coletivos ou difusos dessas pessoas e disciplina a atuação do Ministério Público; a Lei n. 10.048/2000, que trata da prioridade de atendimento em setores públicos e privados; entre outras.

Havia, contudo, necessidade de um compromisso internacional para promoção e proteção dos direitos e da dignidade das pessoas com deficiência. Sendo assim, o Brasil se tornou signatário da Convenção Internacional sobre os Direitos das Pessoas com Deficiência e de seu Protocolo Facultativo, assinados em Nova York (em março de 2007), ratificados pelo Congresso Nacional por meio do Decreto Legislativo n. 186 (em julho de 2008) e promulgados por meio do Decreto n. 6.949, em 25 de agosto de 2009, data de início de sua vigência no plano interno, com status de emenda constitucional (art. $5^{\circ}, \S 3^{\circ}$ da $\mathrm{CF} / 88$ ).

Foi expressamente com base em tal Convenção que se instituiu a Lei Brasileira de Inclusão da Pessoa com Deficiência (Estatuto da Pessoa com Deficiência) - Lei n. 13.146, de 06 de julho de 2015 -, apresentada com o objetivo central, expresso em seu art. $1^{\text {o }}$, de "assegurar e promover, em condições de igualdade, o exercício dos direitos e das liberdades fundamentais por pessoa com deficiência, visando à sua inclusão social e cidadania”.

Importante ressaltar que se adota no presente trabalho a nomenclatura "pessoa com deficiência" que foi a mesma utilizada nos dois textos legislativos mais recentes. Sassaki (2003, p. 8-11) enfatiza que, dentre outros motivos, elas optam por essa expressão: por não esconder ou camuflar a deficiência; mostrar com dignidade a realidade da deficiência, valorizando diferenças e necessidades dela decorrentes; combater eufemismos, tais como "pessoas deficientes" ou "pessoas especiais"; promover a igualdade de oportunidades.

Feito esse esclarecimento, deve-se notar que tanto a Convenção quanto o Estatuto preocupam-se com o acesso à justiça por tais pessoas. Com efeito, a expectativa que se depreende de um dos itens de seu preâmbulo é de que a Convenção representa verdadeiro parâmetro impulsionador de correção das profundas desvantagens sociais vivenciadas por elas

Revista Brasileira de Direitos e Garantias Fundamentais | e-ISSN: 2526-0111 | Porto Alegre | v. 4 | n. 2 | p. $38-60$ | Jul/Dez. 2018 
e de promoção de uma vida econômica, social e cultural, em igualdade de oportunidades, tanto nos países em desenvolvimento como nos desenvolvidos.

Com efeito, Canotilho (2003, p. 430) adverte não se tratar apenas de um princípio do Estado de Direito, podendo e devendo ser considerado princípio de justiça social, assumindo relevo enquanto princípio de igualdade de oportunidades e de condições reais de vida no alicerce do Estado Democrático de Direito.

Está, por conseguinte, atrelado à idéia de igual dignidade da pessoa humana, de modo que, ainda na visão do constitucionalista português, funcionaria não apenas como fundamento contra discriminações, mas, como "princípio jurídico-constitucional impositivo de compensação de desigualdade de oportunidades e como princípio sancionador da violação da igualdade por comportamentos omissivos". (CANOTILHO, 2003, p. 430-431).

No que tange ao objeto específico de estudo deste trabalho, Glasenapp (2016, p. 123) defende a tese de que a igualdade é verdadeiro pressuposto para a concretização da justiça social das pessoas com deficiência. Nesse sentido, a Convenção Internacional sobre os Direitos das Pessoas com Deficiência, em seu art. 13, busca ampliar o referido acesso, atribuindo-lhe parâmetros internacionais de inclusão, acessibilidade e igualdade. Assim:

Os Estados Partes assegurarão o efetivo acesso das pessoas com deficiência à justiça, em igualdade de condições com as demais pessoas, inclusive mediante a provisão de adaptações processuais adequadas à idade, a fim de facilitar o efetivo papel das pessoas com deficiência como participantes diretos ou indiretos, inclusive como testemunhas, em todos os procedimentos jurídicos, tais como investigações e outras etapas preliminares.

Com espelho em tais parâmetros, o Estatuto da Pessoa com Deficiência também dedicou especial atenção ao acesso à justiça, determinando, no caput do art. 79, que se trata de dever do Poder Público, a ser garantido em igualdade de oportunidades com as demais pessoas, assegurando adaptações e recursos de tecnologia assistida sempre que requeridos pelas pessoas com deficiência.

Desse modo, Farias, Cunha e Pinto (2016, p. 216) afirmam que o acesso à justiça garantido às pessoas com deficiência deve estar associado ao princípio da dignidade da pessoa humana, da qual se desdobra a garantia de inclusão social, jurídica e judicial. Não se trata, portanto, apenas de "evitar a discriminação (permitindo que a pessoa com deficiência alcance, por méritos próprios, os seus fins), mas, por igual, criar mecanismos para que tais seres humanos possam acessar, sem embaraços, o Poder Judiciário".

Revista Brasileira de Direitos e Garantias Fundamentais | e-ISSN: 2526-0111 | Porto Alegre | v. 4 | n. 2 | p. $38-60$ | Jul/Dez. 2018 
Como decorrência do compromisso de igualdade de oportunidades, é relevante destacar avanços específicos alcançados no ordenamento jurídico brasileiro, observando-se que, após o advento da Convenção e do Estatuto, somados à promulgação do Novo Código de Processo Civil (Lei n. 13.105, de 16 de março de 2015), muitos deles foram atualizados para se adaptarem aos novos parâmetros estabelecidos.

É nesse contexto que se situa a questão da prioridade na tramitação dos processos judiciais e administrativos. A Lei n. 12.008/2009 garantiu às pessoas com deficiência a prioridade apenas em processos administrativos. O Código de Processo Civil de 2015, em seu art. 1048, não apontou as pessoas com deficiência no rol de prioridades do processo judicial.

Sendo assim, a mais ampla prioridade em tramitação de processos para elas só se consolidou a partir do Estatuto da Pessoa com Deficiência, que determinou expressamente, em seu art. 9', VII, o direito ao atendimento prioritário na "tramitação processual e procedimentos judiciais e administrativos em que for parte ou interessada, em todos os atos e diligências".

Ora, como se observou no tópico inicial do presente trabalho, sob a ótica de Tilly (2013, p. 28), a igualdade é um dos parâmetros para que se aufira o grau de extensão da democracia e cidadania, variando desde uma grande desigualdade entre os cidadãos e categoria de cidadãos, até uma extensiva igualdade em ambos os casos, não havendo distinções.

Nota-se, portanto, que sob a ótica da prioridade para pessoas com deficiência em tramitação de processos judiciais há um indicativo não democrático até passado recente, na medida em que se trata de conquista muito tardia, inclusive se comparada com outros grupos vulneráveis como idosos e crianças / adolescentes.

Mas, afora a questão da prioridade, verifica-se que é preciso estar atento para a utilização de instrumentos processuais para pessoas com deficiência, como sinônimo de ampliação do grau de democratização do acesso à justiça. Nesse sentido, pode ser pontuado o uso da tutela específica, no que tange ao combate à morosidade e à busca por maior efetividade no processo.

Nota-se que houve grande evolução legislativa no Brasil nas últimas décadas até chegar à sistemática atual do Novo Código de Processo Civil: inicialmente, para tutela específica das obrigações de fazer e não fazer (Lei n. 8.952/94); posteriormente, para as de

Revista Brasileira de Direitos e Garantias Fundamentais | e-ISSN: 2526-0111 | Porto Alegre | v. 4 | n. 2 | p. $38-60$ | Jul/Dez. 2018 
entrega de coisa (Lei n. 10.444/2002); e, por fim, para as de pagar (Lei n. 11.232/2005).

Rostelato (2009, p. 98-106) focou sua pesquisa no âmbito individual de prestação jurisdicional às pessoas com deficiência e ressaltou que, muitas vezes a tutela esperada não é uma reparação por perdas e danos. Basta imaginar situações como a de não fornecimento de remédios ou tratamento de saúde adequado pelo Estado, de não disponibilização de meios aptos à inclusão escolar ou de ausência de reservas de vagas em edital de concurso público.

Outras tutelas apontadas por Rostelato (2009, p. 157-187), que podem ser bastante eficazes às pessoas com deficiência, são as de urgência, caso presentes os requisitos legais para concessão. Cumpre observar que aqui também houve grande evolução legislativa no Brasil nas últimas décadas, como a introdução do instituto da tutela antecipada (Lei n. 8.952/94), fungibilidade das tutelas cautelar e antecipada (pela Lei n. 10.444/2002) e a atual sistemática da tutela de urgência e de natureza antecipada do atual Código de Processo Civil.

Sabe-se, contudo, que morosidades ainda são entraves ao acesso à justiça, não solucionados completamente pelas reformas e deve-se refletir que a demora na prestação jurisdicional pode gerar impactos ainda mais severos quando a parte do processo é vulnerável como a pessoa com deficiência, que já enfrenta tantas dificuldades e barreiras em seu dia a dia. Por outro lado, a depender do tipo de tutela, essa não pode ser a única preocupação, já que, como observa Santos (2011, p. 43), "do ponto de vista de uma revolução democrática da justiça, não basta a rapidez. É necessária, acima de tudo, uma justiça cidadã”.

$\mathrm{O}$ acesso à justiça por pessoas com deficiência abarca também a proteção transindividual (difusa ou coletiva), que se dá, em regra, mediante a propositura de ação civil pública, disciplinada pela Lei n. 7.347/1985. Nessa seara, ainda merece destaque a Lei n. 7.853/1989 que, dentre outras medidas inclusivas, instituiu a tutela jurisdicional de interesses das pessoas com deficiência, ressaltando o papel do Ministério Público.

Com efeito, o Ministério Público teve notável ampliação de suas atribuições após a Constituição Federal de 1988, que preconizou, em seu art. 127, tratar-se de "instituição permanente, essencial à função jurisdicional do Estado, incumbindo-lhe a defesa da ordem jurídica, do regime democrático e dos interesses sociais e individuais indisponíveis".

Farias, Cunha e Pinto (2016, p. 227) ressaltam que, à luz do Código de Processo Civil de 2015, a atuação do Ministério Público na defesa dos interesses difusos, coletivos ou individuais homogêneos, deve ser no sentido de solucionar efetivamente a demanda, se 
possível extrajudicialmente. Indica-se a realização de audiências públicas e a utilização do termo de ajustamento de conduta, podendo valer-se, neste caso, dos acordos de procedimentos autorizados pelo art. 190, do CPC/2015. Nesse sentido, Ribeiro (2016, p. 359-362) enfatiza a rapidez da solução de tais medidas com o fito de evitar a judicialização.

Além do Ministério Público, o art. 3º da Lei n. 7.853/1989 teve sua redação alterada pelo Estatuto da Pessoa com Deficiência, passando a incluir a Defensoria Pública entre os legitimados para propositura de medidas judiciais destinadas à proteção de interesses coletivos, difusos, individuais homogêneos e individuais indisponíveis de tais pessoas. Ademais, o $\S 3^{\circ}$ do art. 79, do referido Estatuto, atribui a essas instituições a responsabilidade de tomarem todas as medidas necessárias à garantia dos direitos nele previstos.

Em que pese a inclusão tardia da Defensoria Pública, Val Ribeiro (2016, p. 340-344) ressalta, por outro lado, que não houve vinculação ao termo "hipossuficientes", o que permite a interpretação sistemática e expansiva de que as pessoas com deficiência serão assistidas por esse órgão independentemente de sua situação econômica, reconhecida sua situação de vulnerabilidade social. A autora exemplifica situações em que é possível a atuação da instituição na busca da efetividade dos direitos individuais e coletivos, como transportes adaptados, equipamentos e medicamentos necessários ao tratamento de saúde, fornecimento de prótese, acesso à educação, entre outros.

Santos (2011, p. 51) destaca a relevância da Defensoria Pública para uma revolução democrática da justiça apontando vantagens potenciais como: a assistência prestada por profissionais formados e selecionados para esse fim; a assistência jurídica especializada para defesa de interesses coletivos e difusos; atuação na educação para os direitos.

Por outro lado, aponta problemas a serem solucionados para que tais vantagens se transformem em realidade: as características estruturais, organizacionais e funcionais das defensorias públicas estaduais são muito variáveis de estado para estado; há um desnível na participação no orçamento das defensorias em face do Poder Judiciário e do Ministério Público; a Defensoria Pública da União é limitada; os quadros das defensorias públicas estaduais são muito reduzidos em relação às necessidades da sociedade brasileira. (SANTOS, 2011, p. 53-54).

Em síntese, apesar da atribuição tardia de competência e de suas deficiências estruturais e organizacionais (índices não democráticos), a Defensoria Pública vem se 
fortalecendo no exercício da responsabilidade de tomar medidas necessárias à tutela individual e coletiva dos direitos das pessoas com deficiência, em conjunto com o Ministério Público, o que indica um crescimento potencial de democratização do acesso à justiça.

\section{DESAFIOS ENFRENTADOS POR PESSOAS COM DEFICIÊNCIA AUDITIVA PARA A CONCRETIZAÇÃO DO ACESSO À JUSTIÇA BRASILEIRA: DEMOCRATIZAÇÃO OU DESDEMOCRATIZAÇÃO?}

O conceito de deficiência auditiva é trazido pelo Decreto n. 3.298/1999 e atualizado pelo Decreto $\mathrm{n}^{\mathrm{o}}$ 5.296/2004, nos seguintes termos: "perda bilateral, parcial ou total, de quarenta e um decibéis $(\mathrm{dB})$ ou mais, aferida por audiograma nas freqüências de $500 \mathrm{HZ}$, $1.000 \mathrm{HZ}, 2.000 \mathrm{~Hz}$ e $3.000 \mathrm{~Hz}$.

É preciso observar, contudo, que a Convenção Internacional sobre os Direitos das Pessoas com Deficiência reconhece, em seu preâmbulo, que a deficiência é um conceito em evolução e que "resulta da interação entre pessoas com deficiência e as barreiras devidas às atitudes e ao ambiente que impedem a plena e efetiva participação dessas pessoas na sociedade em igualdade de oportunidades com as demais pessoas".

Com base em tais fundamentos, a referida Convenção define as pessoas com deficiência em seu art. $1^{\circ}$, nos seguintes termos:

\footnotetext{
Pessoas com deficiência são aquelas que têm impedimentos de longo prazo de natureza física, mental, intelectual ou sensorial, os quais, em interação com diversas barreiras, podem obstruir sua participação plena e efetiva na sociedade em igualdades de condições com as demais pessoas.
}

Trata-se, basicamente, do mesmo conceito expresso no art. $2^{\circ}$, do Estatuto da Pessoa com Deficiência. Perceba-se que a necessidade de superar barreiras integra a mais atualizada definição dessas pessoas. Note-se, também, que o conceito é evolutivo e diretamente relacionado à inclusão social em igualdade de oportunidades.

Ora, é assim que também deve ser interpretado e aplicado o conceito de pessoa com deficiência auditiva, não se pautando apenas em aspectos físicos, mas, principalmente, em sua participação plena e efetiva na sociedade. Foi com base em tais reflexões que, propositadamente, se reservou a abordagem do referido conceito para o presente tópico, em que se passa a discutir seus desafios para a concretização do acesso à justiça no Brasil.

Revista Brasileira de Direitos e Garantias Fundamentais | e-ISSN: 2526-0111 | Porto Alegre | v. 4 | n. 2 | p. 38 - 60 | Jul/Dez. 2018 
É que, apesar de todos os progressos apontados, muitas barreiras sociais e atitudinais ainda precisam ser enfrentadas e vencidas para garantia do mais amplo acesso à justiça por pessoas com deficiência auditiva. Nesse sentido, ao comentar o artigo 13, da Convenção Internacional sobre os Direitos das Pessoas com Deficiência (que trata do acesso à justiça), Costa Filho (2014, p. 94) é enfático ao afirmar:

Ocorre que muito ainda há a fazer, e ainda há muitas imperfeições no sistema
judiciário que emperram ou obstaculizam o devido processo legal à pessoa com
deficiência, o que muita vezes inviabiliza a realização da tão almejada justiça. A
Convenção dos Direitos das Pessoas com Deficiência, como norma fundamental e
essencial para a dignidade e cidadania desse segmento ainda marginalizado, precisa
ser mais disseminada no mundo jurídico, a fim de que seja realmente aplicada no
seu todo, formando jurisprudência, inclusive súmulas vinculantes, que transformem
nossa Justiça e seus membros, reconhecendo a deficiência como algo relevante em
nosso País democrático.

Ademais, é preciso relembrar o alerta de Tilly (2013, p. 21) com relação às abordagens constitucionais de democracia e a possibilidade de discrepâncias entre os princípios afirmados e as práticas cotidianas. Isso se coaduna com a observação de Gagliano (2016) de que "o grande desafio é a mudança de mentalidade, na perspectiva de respeito à dimensão existencial do outro. Mais do que leis, precisamos mudar mentes e corações”.

Com efeito, é preciso refletir que, segundo dados do Instituto Brasileiro de Geografia e Estatística, 45.606.048 brasileiros têm algum tipo de deficiência - visual, auditiva, motora e mental ou intelectual. Isso representa $23,9 \%$ da população brasileira, sendo que a deficiência auditiva está presente em 5,10\%. Mas, segundo a Cartilha do Censo 2010 (p. 14), tais pessoas nem sempre conseguem alcançar o cumprimento de seus direitos nas mesmas condições das pessoas sem deficiência, por conta das desvantagens impostas pela restrição de funcionalidade e pela própria sociedade que lhes impõe barreiras físicas e de atitude.

No caso específico das pessoas com deficiência auditiva, tal situação se mostra ainda mais grave quando se pensa que apenas em 24 de abril de 2002 a Lei n. 10.436 reconheceu como meio legal de comunicação e expressão a Língua Brasileira de Sinais - Libras e outros recursos de expressão a ela associados, conceituando-a, no parágrafo único do art. $1^{\text {o }}$ como "a forma de comunicação e expressão, em que o sistema lingüístico de natureza visual-motora, com estrutura gramatical própria, constituem um sistema lingüístico de transmissão de idéias e fatos, oriundos de comunidades de pessoas surdas do Brasil”.

Em conformidade com o art. $2^{\circ}$ da referida lei, uma vez reconhecida como língua

Revista Brasileira de Direitos e Garantias Fundamentais | e-ISSN: 2526-0111 | Porto Alegre | v. 4 | n. 2 | p. $38-60$ | Jul/Dez. 2018 
oficial, compete ao Poder Público difundir o seu uso como meio de comunicação objetiva e de utilização corrente das comunidades surdas do Brasil. Nesse sentido, cumpre refletir:

\begin{abstract}
O apoio em questão não é mera exortação, implica respeito e aplicação prática, de modo a assegurar ao cidadão surdo o direito de livre expressão e de comunicação, estabelecendo a ruptura das fronteiras atitudinais que separavam, até então, a comunidade surda brasileira da nação brasileira. Essa comunidade se compõe de cidadãos brasileiros surdos que, até hoje, porém, não exercem plenamente sua cidadania, porque a nossa sociedade era e é deficiente no sentido de estabelecer uma interlocução plena com eles, capaz de lhes assegurar os direitos humanos fundamentais decorrentes da livre expressão do pensamento, que se perfaz apenas com a comunicação. (FONSECA, 2010).
\end{abstract}

Ora, como se pode pensar em democratização do acesso à justiça por pessoas com deficiência auditiva quando o próprio Estado Brasileiro retarda de tal maneira o reconhecimento legal de seu principal meio de comunicação? Sem um efetivo meio de comunicar-se, ou com um meio não reconhecido, haveria como se falar nas tais consultas amplas, igualitárias, protegidas e mutuamente vinculantes propostas por Tilly?

É instigante perceber que em pleno ano vigente, mais especificamente em 14 de março de 2018, o Conselho Nacional de Justiça do Brasil ainda veicule, em tom de comemoração, notícias como "Uso de Libras no Poder Judiciário avança no País". Na notícia a autora Thaís Cieglinski informa que em agosto de 2017, o Tribunal de Justiça da Bahia protagonizou um acontecimento inédito: a juíza Márcia Cristie Leite Vieira, titular da Vara do Tribunal do Júri de Itabuna promoveu o primeiro julgamento com tradução em Libras do Brasil, em caso em que não envolvia pessoa com deficiência como participante do processo.

Mais alarmante ainda é a fala da magistrada apresentada na referida entrevista: "Acho que foi o momento mais bonito da minha carreira, pois não tinha ideia do interesse dos surdos em participar do mundo jurídico. Tenho muito orgulho de ter realizado esse Júri”. Discursos como este refletem o grau de extensão do processo de democratização tardia e lenta, ou em alguns aspectos, quiçá inexistente, que o Brasil vivencia no que tange ao acesso à justiça por pessoas com deficiência auditiva.

Mais recentemente, o site do Conselho Nacional de Justiça do Brasil reproduziu a seguinte notícia do site do Tribunal de Justiça do Rio de Janeiro, informando que tal tribunal realizou, no dia 12/07/2018 a primeira sessão de mediação com intérprete de libras, realizada no Centro Judiciário de Solução de Conflitos e Cidadania (CEJUSC) do Fórum da Leopoldina, em Olaria, Zona Norte do Rio de Janeiro. Tal notícia denuncia, igualmente, o

Revista Brasileira de Direitos e Garantias Fundamentais | e-ISSN: 2526-0111 | Porto Alegre | v. 4 | n. 2 | p. $38-60$ | Jul/Dez. 2018 
quanto a ausência de meios de comunicação prejudicou durante anos o acesso a meios alternativos de solução de conflitos por pessoas com deficiência auditiva no Brasil.

Deve-se notar que apenas em 16/12/2009, o Conselho Nacional de Justiça (CNJ) aprovou a Recomendação n. 27, que foi convolada na Resolução $\mathrm{n}^{\circ} 230$, também de forma tardia, em 20/06/2016, com o objetivo de orientar a adequação das atividades dos órgãos do Poder Judiciário e auxiliares às determinações trazidas pela Convenção Internacional sobre os Direitos das Pessoas com Deficiência e pelo Estatuto da Pessoa com Deficiência.

A Resolução apresenta a obrigação de serem instituídas por cada Tribunal, no prazo máximo de 45 (quarenta e cinco) dias, Comissões Permanentes de Acessibilidade e Inclusão, com caráter multidisciplinar, com participação de magistrados e servidores, com e sem deficiência, objetivando a fiscalização, planejamento, elaboração e acompanhamento dos projetos arquitetônicos de acessibilidade e projetos "pedagógicos" de treinamento e capacitação dos profissionais e funcionários que trabalhem com as pessoas com deficiência.

No caso específico das pessoas com deficiência auditiva, basicamente foram mantidas as propostas de Recomendação, como a necessidade de sinalizações visuais acessíveis a tais pessoas, em conformidade com as regras da ABNT. Outra medida relevante é a habilitação de servidores em cursos oficiais de Linguagem Brasileira de Sinais, custeados pela Administração, para assegurar que as secretarias e cartórios das Varas e Tribunais disponibilizem pessoal capacitado a atender a pessoa com deficiência auditiva.

No mesmo sentido, garante-se a nomeação de tradutor e intérprete de Linguagem Brasileira de Sinais, sempre que figurar no processo pessoa com deficiência auditiva, o qual deverá prestar compromisso e, em qualquer hipótese, será custeado pela administração dos órgãos do Judiciário.

Ademais, sendo a pessoa com deficiência auditiva partícipe do processo oralizado, a referida Resolução, numa perspectiva de cooperação do juiz com o processo, apresenta-lhe a opção de se comunicar por anotações escritas ou por meios eletrônicos, o que inclui a legenda em tempo real, bem como de adotar medidas que viabilizem a leitura labial. A Resolução assegura, ainda, o registro da audiência, caso o magistrado entenda necessário, por filmagem de todos os atos nela praticados, sempre que presente pessoa surda.

No que tange especificamente ao processo eletrônico, a Resolução determina, também, que os órgãos do Poder Judiciário deverão, com urgência, proporcionar aos seus 
usuários um processo adequado e acessível a todos os tipos de deficiência, inclusive a auditiva. Ora, desde 2006 a Lei n. 11.419 previu a informatização do processo judicial brasileiro, determinando o uso de meio eletrônico na tramitação processual, comunicação de atos e transmissão de peças, sob o pressuposto da busca pela mais ampla tutela jurisdicional efetiva. É no mínimo paradoxal falar em urgência ante o retardo de mais de uma década na implantação de tais medidas, em especial para as pessoas com deficiência visual.

O Conselho Nacional do Ministério Público (CNMP) também aprovou a Resolução n. 81, de 31 de janeiro de 2012, dispondo sobre a criação da Comissão Temporária de Acessibilidade, adequação das edificações e serviços do Ministério Público da União e dos Estados às normas de acessibilidade.

Dentre outras medidas, similares às apresentadas pelo $\mathrm{CNJ}$, tal resolução determina, por exemplo, que tais instituições referidas possuam, pelo menos, um telefone de atendimento adaptado para comunicação com e por pessoas com deficiência auditiva. Mas, diferente do que ocorreu com o CNJ, tal Resolução do CNMP não passou por uma revisão à luz do Estatuto da Pessoa com Deficiência e a novas normas da ABNT, demandando atualização.

Ademais, há de se observar que, apesar dos avanços (ainda que tardios) na legislação e atuações do Conselho Nacional de Justiça e do Conselho Nacional do Ministério Público, ainda há muito a melhorar para que se garanta efetivo, democrático e igualitário acesso à justiça por pessoas com deficiência auditiva. Nesse sentido:

Aos surdos aplica-se, é claro, o artigo $5^{\circ}$ da Constituição em todas as suas nuances,
mas à medida que se lhes negue o acesso à Jurisdição, por meio da LIBRAS, não se
lhes garante um Juiz que seguramente conheça a demanda ou que seguramente
entenda a sua defesa, sequer o contraditório e a ampla defesa, por falta de
comunicação entre o surdo e o seu advogado, muito menos uma atuação coerente do
Ministério Público incapaz de ir em direção às demandas da comunidade surda
brasileira a fim de defendê-la, quando necessário for. (FONSECA, 2010).

Como se percebe, as barreiras não se restringem à acessibilidade aos órgãos do Ministério Público ou do Poder Judiciário e suas dependências. Talvez a pessoa com deficiência auditiva sequer conheça seus direitos ou os caminhos para reivindicá-los.

Corroborando com tal pensamento, Souza (2011, p. 26-27) nota que o problema do acesso à justiça no Brasil começa no plano educacional, na medida em que parte da possibilidade de conhecer os direitos e, quando violados, os mecanismos para exercê-los. O autor é enfático ao afirmar que "a realidade é que o cidadão desprovido de educação 
normalmente ignora os direitos que tem, não sabe se seus direitos foram violados e nem como buscar tutelá-los em caso de violação".

Dados do Censo 2010 revelam, por exemplo, que a taxa de alfabetização no Brasil, para a população total, foi de $90,6 \%$, enquanto a do segmento de pessoas com deficiência foi de $81,7 \%$. Com relação ao nível de instrução, a diferença fica ainda maior, já que $61,1 \%$ da população de quinze ou mais anos de idade que apresenta pelo menos uma deficiência não possui instrução ou ensino fundamental completo; e esse percentual se reduz para 38,2\% no caso de pessoas sem deficiência.

Esses problemas educacionais afetam diretamente o acesso à justiça e isso se agrava ainda mais quando se percebe que não são garantidos requisitos mínimos de democracia e cidadania, como a amplitude e a igualdade - apregoadas por Tilly (2013, p. 28) -, na medida em que as pessoas com deficiência têm ainda menos acesso à educação que as pessoas sem deficiência.

Foi refletindo sobre essa igualdade de oportunidades advinda da educação que os delegados da Conferência Mundial de Educação Especial, representando 88 governos e 25 organizações internacionais se reuniram, entre 7 e 10 de junho de 1994, para elaborar a Declaração de Salamanca, reconhecendo a necessidade e urgência de providenciar a educação para as crianças, jovens e adultos com deficiência dentro do sistema regular de ensino.

Ainda sobre a educação das pessoas com deficiência e seus reflexos no acesso à justiça, não se pode deixar de observar a Ação Direta de Inconstitucionalidade n. 5.357, impetrada pela Confederação Nacional dos Estabelecimentos de Ensino (CONFENEN), em 05 de agosto de 2015, questionando a constitucionalidade dos artigos $28, \S 1^{\circ}$, e 30 , caput, do Estatuto da Pessoa com Deficiência, que estabelecem a obrigatoriedade de escolas privadas promoverem a inserção destas pessoas no ensino regular e prover medidas de adaptação necessárias sem que o ônus financeiro seja repassado às mensalidades e matrículas.

A autora da ação alegou, em síntese, que as obrigações impostas às escolas privadas configuram afronta ao direito de propriedade e à liberdade de iniciativa, além de se tratar de obrigação exclusiva do Estado e da família prover educação às pessoas com deficiência. Argumentou-se, ainda, que os dispositivos legais questionados estabelecem medidas de alto custo para as escolas, podendo ocasionar, inclusive, o fim das atividades da maior parte delas.

A maioria dos ministros, contudo, seguiu o voto do Relator, Min. Edson Fachin, para

Revista Brasileira de Direitos e Garantias Fundamentais | e-ISSN: 2526-0111 | Porto Alegre | v. 4 | n. 2 | p. $38-60$ | Jul/Dez. 2018 
decidir pela constitucionalidade dos questionados dispositivos do Estatuto da Pessoa com Deficiência, compreendendo que esta norma reflete o compromisso ético de acolhimento e pluralidade democrática determinados pela Constituição Federal de 1988, tratando-se de obrigação não apenas das escolas públicas, mas também das particulares, a atuação a partir de todas as facetas e potencialidades do direito fundamental à educação.

Em síntese, por tudo quanto exposto, é possível constatar que é recente, lento e paulatino o processo de democratização do acesso à justiça por pessoas com deficiência auditiva no Brasil quando se percebe que elas tem acesso tardio a direitos e à justiça, seja no plano legislativo, seja nas práticas estatais e/ou em sua vivência em sociedade. Além disso, barreiras educacionais podem refletir um não acesso.

Com efeito, levando-se em consideração os critérios de amplitude e igualdade apontados por Charles Tilly, pode-se perceber que, apesar de avanços constatados no presente trabalho, essas pessoas ainda enfrentam problemas básicos na concepção de sua cidadania. Ademais, é preciso refletir em que medida o Estado tem assumido obrigações claras e instituídas de conceder os benefícios devidos às pessoas com deficiência auditiva.

\section{CONSIDERAÇÕES FINAIS}

No desenvolver dessa pesquisa constatou-se que Charles Tilly aufere o grau de democracia analisando a extensão na qual o Estado se comporta diante das demandas expressas por seus cidadãos, sob a égide dos critérios da amplitude, igualdade, proteção e caráter mutuamente vinculante. Em síntese, a democratização é vista como a média de um movimento crescente nessas quatro dimensões, enquanto a desdemocratização, por decorrência lógica, pauta-se no movimento médio decrescente.

Verificou-se que a igualdade de oportunidades é verdadeiro pressuposto para que se promova o acesso democrático à justiça de pessoas com deficiência. A Convenção Internacional sobre os Direitos das Pessoas com Deficiência atribui parâmetros internacionais (espelhados pelo Estatuto da Pessoa com Deficiência), que estabelecem a necessidade de adaptações processuais inclusivas que se estendam por todo e qualquer procedimento jurídico e independentemente da forma como essas pessoas participem do processo.

Destacou-se, ainda, avanços legislativos gerais que podem ser efetivos para as

Revista Brasileira de Direitos e Garantias Fundamentais | e-ISSN: 2526-0111 | Porto Alegre | v. 4 | n. 2 | p. $38-60$ | Jul/Dez. 2018 
pessoas com deficiência, como o uso da tutela específica ou das tutelas de urgência e antecipada, apontados para soluções criativas com os instrumentos vigentes no sentido de ampliar o processo de democratização do acesso à justiça por tais pessoas.

Refletindo especificamente, notou-se, entretanto, que sob a ótica da prioridade para pessoas com deficiência em tramitação de processos judiciais há um indicativo não democrático até passado recente, na medida em que se trata de conquista muito tardia, inclusive se comparada com outros grupos vulneráveis como idosos e crianças / adolescentes.

Por outro lado, apesar da atribuição morosa de competência e das déficits estruturais e organizacionais (aspectos não democráticos), a Defensoria Pública vem se fortalecendo no exercício da responsabilidade de tomar medidas necessárias à tutela individual e coletiva dos direitos das pessoas com deficiência, em conjunto com o Ministério Público, o que indica um crescimento potencial de democratização do acesso à justiça.

Ponderou-se, ainda, que apesar das inovações legislativas, gerais ou específicas, e de iniciativas como as do Conselho Nacional de Justiça e do Conselho Nacional do Ministério Público, dados governamentais e notícias da prática jurídica revelam que ainda há muito que melhorar na sociedade e na organização estatal brasileira, para que se garanta democrático acesso à justiça de pessoas com deficiência auditiva.

Nesse sentido, remeteu-se ao alerta de Charles Tilly com relação às abordagens constitucionais de democracia e a possibilidade de discrepâncias entre os princípios afirmados e as práticas cotidianas. Com efeito, para além das garantias legislativas e constitucionais, há uma necessidade de superar barreiras sociais e atitudinais que integra a própria definição das pessoas com deficiência, numa perspectiva evolutiva e diretamente relacionada à inclusão social em igualdade de oportunidades.

Ressaltou-se, também, que no que tange ao acesso à justiça, essas barreiras não se restringem à acessibilidade aos órgãos do Ministério Público, Defensoria ou do Poder Judiciário. É que talvez a pessoa com deficiência auditiva sequer conheça seus direitos ou os caminhos para reivindicá-los. Nesse sentido, os problemas educacionais afetam diretamente o acesso à justiça e isso se agrava ainda mais quando se percebe que não são garantidos requisitos mínimos de democracia e cidadania, como a amplitude e a igualdade - apregoadas por Tilly -, na medida em que as pessoas com deficiência têm ainda menos acesso à educação que as pessoas sem deficiência.

Revista Brasileira de Direitos e Garantias Fundamentais | e-ISSN: 2526-0111 | Porto Alegre | v. 4 | n. 2 | p. 38 - 60 | Jul/Dez. 2018 
Sendo assim, por tudo quanto exposto, é possível constatar que é relativamente recente e ainda avança paulatinamente o processo de democratização do acesso à justiça por pessoas com deficiência auditiva no Brasil, seja por conta do reconhecimento legal tardio da Língua Brasileira de Sinais, seja pela falta de comprometimento do Estado autoproclamado Democrático de Direito em fazer cumprir direitos fundamentais básicos do cidadão surdo como a educação.

Com efeito, levando-se em consideração os critérios apontados por Charles Tilly, pode-se perceber que, apesar de avanços constatados no presente trabalho, essas pessoas ainda enfrentam problemas básicos na concepção de sua cidadania. Ademais, é preciso refletir em que medida o Estado tem assumido obrigações claras e instituídas de conceder os benefícios devidos às pessoas com deficiência auditiva.

Em síntese, à luz do pensamento de Charles Tilly, arrisca-se afirmar que, em que pese a autoproclamada democracia e as garantias de direitos fundamentais previstos na Constituição Federal de 1988, o Brasil passa por lento processo de democratização no que tange ao acesso à justiça por pessoas com deficiência auditiva, por conta da acessibilidade tardia a direitos e à justiça (se é que já se pode falar que os tem), seja no plano legislativo, seja nas práticas institucionais e estatais, ou em sua vivência em sociedade de forma mais ampla.

\section{REFERÊNCIAS}

BRASIL. Conselho Nacional de Justiça (CNJ). Resolução n. 230, de 22 de junho de 2016. Disponível em: <http://www.cnj.jus.br >. Acesso em: 09 de setembro de 2018.

BRASIL. Conselho Nacional do Ministério Público (CNMP). Resolução n. 81, de 31 de janeiro de 2012. Disponível em: 〈http://www.cnmp.mp.br>. Acesso em: 18 de agosto de 2018.

BRASIL. Secretaria de Direitos Humanos da Presidência da República (SDH/PR) / Secretaria Nacional de Promoção dos Direitos da Pessoa com De ciência (SNPD). Cartilha do Censo 2010 - Pessoas com deficiência. Brasília: SDH-PR / SNPD, 2012. Disponível em: <http://www.pessoacomdeficiencia.gov.br>. Acesso em: 18 de agosto de 2018.

BRASIL. Supremo Tribunal Federal. Ação Direta de Inconstitucionalidade n. 5357 MCRef / DF. Requerente: Confederação Nacional dos Estabelecimentos de Ensino CONFENEN. Relator: Min. Edson Fachin. Brasília, 9 de junho de 2016. Disponível em: <http://stf.jus.br >. Acesso em: 18 de agosto de 2018.

Revista Brasileira de Direitos e Garantias Fundamentais | e-ISSN: 2526-0111 | Porto Alegre | v. 4 | n. 2 | p. $38-60$ | Jul/Dez. 2018 
BRASIL. Supremo Tribunal Federal. Escolas particulares devem cumprir obrigações do Estatuto da Pessoa com Deficiência, decide STF. Brasília, 9 de junho de 2016. Disponível em: 〈http://www.stf.jus.br〉. Acesso em: 18 de agosto de 2018.

CAPPELlETTI, Mauro; GARTH, Bryant. Acesso à justiça. Tradução e revisão de Ellen Gracie Northfleet. Porto Alegre: Sergio Antonio Fabris Editor, 1988.

CANOTILHO, J. J. Gomes. Direito constitucional e teoria da constituição. 7. ed. Coimbra: Almedina, 2003.

CIEGLINSKI, Thaís. Uso de Libras no Poder Judiciário avança no País. Disponível em: <http://www.cnj.jus.br/noticias/cnj/86329-uso-de-libras-no-poder-judiciario-avanca-no-pais>. Acesso em: 09 de setembro de 2018.

COSTA FILHO, Waldir Macieira da. Artigo 13. Acesso à justiça. In: BRASIL. Secretaria de Direitos Humanos da Presidência da República (SDH/PR) / Secretaria Nacional de Promoção dos Direitos da Pessoa com De ciência (SNPD). Novos Comentários à Convenção sobre os Direitos das Pessoas com Deficiência. 2014. Disponível em: <http://www.pessoacomdeficiencia.gov.br>. Acesso em: 18 de agosto de 2018, p. 90-97.

DAHL, Robert A. Sobre a democracia. Tradução de Beatriz Sidou. Brasília: Editora Universidade de Brasília, 2009.

DÍAZ, Elías. Estado de direito e sociedade democrática. Tradução de Antonio Guimarães. Lisboa: Iniciativas Editoriais, 1969.

FARIAS, Cristiano Chaves; CUNHA, Rogério Sanches; PINTO, Ronaldo Batista. Estatuto da Pessoa com Deficiência Comentado artigo por artigo. Salvador: Ed. JusPodivm, 2016.

FONSECA, Ricardo Tadeu Marques da. Libras no Judiciário: um débito social. Disponível em: 〈http://www.inclusive.org.br/arquivos/13321>. Acesso em: 09 de setembro de 2018.

GAGLIANO, Pablo Stolze. O Estatuto da Pessoa com Deficiência e o sistema jurídico brasileiro de incapacidade civil. Revista Jus Navigandi, ISSN 1518-4862, Teresina, ano 20, n. 4411, 30 jul. 2015. Disponível em: <https://jus.com.br/artigos/41381>. Acesso em: $17 \mathrm{de}$ agosto de 2018.

GLASENAPP, Ricardo. A igualdade como idéia de justiça social para pessoas com deficiência nas decisões do Supremo Tribunal Federal. 1. ed. Curitiba: Editora Prismas, 2016.

RIBEIRO, Lauro Luiz Gomes. O papel do Ministério Público na defesa dos interesses da pessoa com deficiência (art. 79, § $3^{\circ}$ ). In: LEITE, Flávia Piva Almeida; RIBEIRO, Lauro Luiz Gomes; COSTA FILHO, Waldir Macieira da Costa Filho (coords.). Comentários ao Estatuto da Pessoa com Deficiência. São Paulo: Saraiva, 2016. 
ROSTELATO, Telma Aparecida. Portadores de deficiência e prestação jurisdicional. Curitiba: Juruá, 2009.

SANTOS, Boaventura de Sousa. Para uma revolução democrática da justiça. 3. ed. São Paulo: Cortez, 2011.

SASSAKI, Romeu Kazumi. Como chamar as pessoas que têm deficiência? Revista da Sociedade Brasileira de Ostomizados, ano I, n. 1, $1^{\circ}$ sem. 2003, p. 8-11. [Texto atualizado em 2009].

SILVA, José Afonso da. O Estado democrático de Direito. Revista de Direito Administrativo, Rio de Janeiro, n. 173, jul./set., 1988.

SOUZA, Wilson Alves de. Acesso à justiça. Salvador: Dois de Julho, 2011.

TILLY, Charles. Democracia. Tradução de Raquel Weiss. Petrópolis, RJ: Vozes, 2013. (Coleção sociologia).

VAL RIBEIRO, Juliana do. O papel da Defensoria Pública na defesa dos interesses da pessoa com deficiência (art. 79, § $3^{\circ}$ ). In: LEITE, Flávia Piva Almeida; RIBEIRO, Lauro Luiz Gomes; COSTA FILHO, Waldir Macieira da Costa Filho (coords.). Comentários ao Estatuto da Pessoa com Deficiência. São Paulo: Saraiva, 2016. 